to dichloroacetate. The degree of counterion dissociation is largest for decylammonium acetate and therefore the negative entropy contribution is reduced to a higher degree when increasing the surfactant concentration.

\section{Conclusions}

It is demonstrated that the Fourier transform NMR self-diffusion technique gives direct and easy access to information on organic counterion binding to micelles even in the presence of several counterions. The degree of counterion binding, the $\mathrm{cmc}$, and the free amphiphile concentration above cmc were demonstrated to be distinctly different for decylammonium acetate, chloroacetate, and dichloroacetate. In a competitive situation, an amplification of the differences in ion binding was demonstrated.

Registry No. Decylammonium acetate, 2016-38-8; decylammonium chloroacetate, 78961-19-0; decylammonium dichloroacetate, 98087-68-4.

\title{
Vapor-Phase Dipole Moment Values from Solution Measurements
}

\author{
Máximo Barōn ${ }^{\dagger}$ \\ Departamento de Física, Facultad de Ciencias Exactas y Naturales, Universidad de Buenos Aires, Pabellön 1 , \\ C. Universitaria, 1428 Buenos Aires, Argentina (Received: March 4, 1985; In Final Form: June 27, 1985)
}

\begin{abstract}
An equation proposed by $\mathrm{H}$. Mechetti to describe the permittivity of very dilute polar/nonpolar solutions as a function of concentration was used to calculate the molecular dipole moment of the solutes. The procedure is very simple, and the results are in good agreement with those obtained through more elaborate known methods. Furthermore, an adequate choice of solvents leads to results that are in very good agreement with the corresponding vapor-phase values.
\end{abstract}

\section{Introduction}

The molecular dipole moment, as a very useful parameter for structural studies, should ideally be calculated from vapor-phase measurements, to avoid any kind of intermolecular interactions. This is only possible with compounds that have a vapor pressure high enough to allow them to be handled as vapors in the measuring devices. Therefore, the number of compounds that can be studied is limited.

To overcome this problem, calculations have been proposed based on measurements made on very dilute solutions of the candidate substance in nonpolar solvents. It was assumed that under these conditions there would be no solute/solute or solute/solvent interactions.

The first equation proposed by Peter J. W. Debye ${ }^{1}$ in 1921 was followed by others that have been extensively described and discussed in the literature. ${ }^{2}$ The initial success of such equations was attributed to the absence of interactions. This appeared to be confirmed by the linear behavior, at very high dilutions, of permittivity $(\epsilon)$, density $(d)$ (or specific volume $\bar{V}$ ), and the refractive index $(n)$ as a function of concentration. However, comparing solution and vapor-phase measurements on low-temperature boiling compounds, we found discrepancies in some cases as high as $30 \%$ (chloroform $^{3}$ ), although in general they are between $8 \%$ and $15 \%$ (water, nitromethane, methanol, trichloroethane, and acetone $e^{4}$. This was originally attributed to a so-called solvent effect that has been carefully discussed over the years since $1934,{ }^{5}$ under the more adequate denomination of solute/solvent interactions or solvation. ${ }^{6}$ The latter appears to be the cause for the differences observed between vapor-phase and solution values.

It is a known fact that for dilute binary liquid systems the permittivity $(\epsilon)$ is a linear function of concentration. However, due to the above-mentioned interactions, this behavior cannot be described by a simple additive law. This was discussed in a previous paper, ${ }^{7}$ and as a result, eq I was proposed by $\mathrm{H}$. Mechetti based on a model that proved adequate for the permittivity of dilute solutions of water and lower alcohols in nonpolar solvents:

$$
\begin{aligned}
\epsilon_{12}=\epsilon_{1}+4 \pi\left\{\begin{aligned}
\frac{\left(n_{2}^{2}+2\right)\left(2 \epsilon_{1}+1\right) \epsilon_{1}\left(n_{2}{ }^{2}+2\right) \mu_{0}{ }^{2}}{3\left(2 \epsilon_{1}+n_{2}{ }^{2}\right) 2\left(\epsilon_{1}+n_{2}{ }^{2}\right) 3 k T}+ \\
\frac{\left(n_{2}{ }^{2}-1\right)}{\left(n_{2}{ }^{2}+2\right)} a^{3}+\left[0.15 \frac{\left(n_{2}{ }^{2}-1\right)}{\left(n_{2}{ }^{2}+2\right)} a_{2}{ }^{3}\right]
\end{aligned}\right\} N_{2}
\end{aligned}
$$

\footnotetext{
${ }^{\dagger}$ Member of the Carrera del Investigador Cientifico, CONICET.
}

In this equation, $\epsilon_{1}$ is the permittivity of the pure solvent, $\epsilon_{12}$ the permittivity of the solution, $n_{2}{ }^{2}$ the refractive index of the pure solute (squared), $a_{2}$ the radius of the molecule calculated from the experimental specific volume $(\bar{V}), N_{2}$ the solute concentration expressed as the number of molecules per milliliter of solution, $\mu_{0}$ the vapor-phase dipole moment of the solute molecule, $k$ Boltzmann's constant, and $T$ the temperature.

If $\epsilon_{1}, n_{2}, \bar{V}_{2}$, and $\epsilon_{12}$ are measured, eq I can be rearranged to calculate $\mu_{0}$ :

$$
\mu_{0}=\left[\frac{\left[\frac{\left(\epsilon_{12}-\epsilon_{1}\right)}{4 \pi N_{2}}-1.15 a_{2}{ }^{3} \frac{\left(n_{2}{ }^{2}-1\right)}{\left(n_{2}{ }^{2}+2\right)}\right] 3 k T}{\frac{\left(n_{2}{ }^{2}+2\right)\left(2 \epsilon_{1}+1\right) \epsilon_{1}\left(n_{2}{ }^{2}+2\right)}{3\left(2 \epsilon_{1}+n_{2}{ }^{2}\right)\left(2 \epsilon_{1}+n_{2}{ }^{2}\right)}}\right]^{1 / 2}
$$

Equation II indicates that vapor-phase values of the molecular dipole moment could be calculated from single solution measurements. The procedure is very simple since no additional calculations are necessary, like permittivity and specific volume slopes or total polarization values, as is the case with other well known methods (i.e., that of Halverstadt and $\mathrm{Kumler}^{8}$ ).

(1) Peter W. J. Debye, "Polar Molecules", Dover Publications Inc., New York, 1921

(2) H. Bradford Thompson, J. Chem. Educ., 43, 66 (1966).

(3) A. L. McClellan, "Tables of Experimental Dipole Moments", Vol. 2, Rahara Enterprises, El Cerrito, CA, 1974, p 45.

(4) A. L. McClellan, ref 3, pp 25, 42, 42, 64, 82.

(5) F. Horst Mueller, Trans. Faraday Soc., 30, 729 (1934).

(6) S. D. Christian, A. A. Taha, and D. W. Gash, Rev. Chem. Soc., 24, $20(1970)$

(7) M. Barôn and H. Mechetti, J. Phys. Chem., 86, 3464 (1982).

(8) J. F. Halverstadt and W. D. Kumler, J. Am. Chem. Soc. 64, 2988 (1942).

(9) A. B. Lindenberg, C. R. Seances Acad. Sci., Ser. C, 262, 1504 (1966).

(10) M. Barôn, An. Asoc. Quim. Argent., 67, 203 (1979).

(11) H. Lumbroso and C. Andrieu, Bull. Soc. Chim. Fr., 3201 (1966).

(12) A. A. Abdurakhmanov, R. A. Regimova, and L. M. Imanov, Phys. Lett. A, 32A, 123 (1970).

(13) J. P. de Jongh and H. A. Dijkerman, J. Mol. Spectrosc., 25, 129 (1968).

(14) H. Loozenga, Mol. Phys., 9, 501 (1965).

(15) S. Weiss, J. Phys. Chem., 70, 3146 (1966).

(16) R. Holm, M. Mitzlaff, and H. Hartmann, Z. Naturforsch, A: Astrophys., Phys. Phys. Chem., 23A, 307 (1968). 

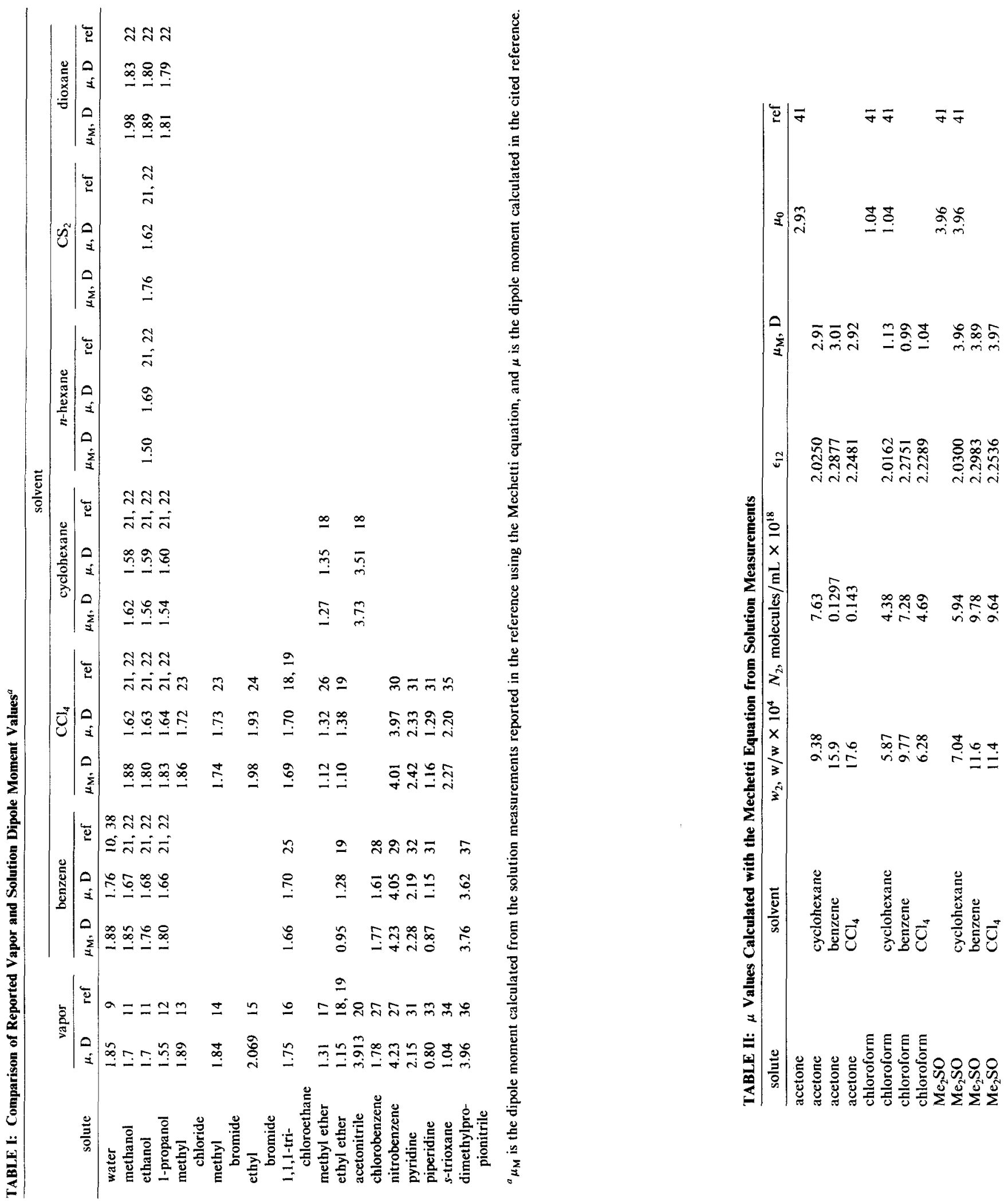


\section{Examination of Data}

To verify the above assumption, data reported in the literature on a variety of solutes studied in different solvents were used to calculate the vapor-phase molecular dipole moment $\left(\mu_{0}\right)$ with a suitable computer program. The results are listed in Table I and show that, in general, with eq II the solution measurements give numbers that are close to the vapor-phase values.

Furthermore, additional evidence was obtained experimentally for acetone, chloroform, and $\mathrm{Me}_{2} \mathrm{SO}$.

\section{Experimental Part}

Spectrograde candidate substances were dissolved in solvents purified as reported elsewhere. ${ }^{40}$ Permittivity, specific volume, and refractive indices were also measured as described. ${ }^{40}$ Dilute (1963)

(17) U. Blukis, P. H. Kasai, and R. J. Myers, J. Chem. Phys, 38, 2753

(18) R. J. W. Le Fevre, D. V. Radford, G. L. Ritchie, and J. P. Stiles, J. Chem. Soc. B, 148 (1968).

(19) A. N. Sharpe and S. Walker, J. Chem. Soc., 3274 (1964).

(20) P. A. Steiner, Diss. Abstr., 26, 423 (1965).

(21) D. A. Ibbitson and L. F. Moore, J. Chem. Soc. B, 76 (1968)

(22) R. H. Stokes and K. N. Marsh, J. Chem. Thermodyn., 8, 709 (1976).

(23) C. G. Le Fevre and R. J. W. Le Fevre, J. Chem. Soc., 1585 (1954)

(24) R. J. W. Le Fevre and A. J. Williams, J. Chem. Soc., 4185 (1965)

(25) R. J. W. Le Fevre and G. L. D. Ritchie, J. Chem. Soc., 4933 (1963) (1962)

(27) R. L. Poynter, J Chem Phys, 39, 1962 (1963).

(28) R. J. Bishop, L. E. Sutton, D. Dineen, R. A. Y. Jones, A. R. Katritzky, and R. J. Wyatt, J. Chem. Soc. B, 493 (1967).

(29) R. J. W. Le Fevre and P. Russell, J. Chem. Soc., 491 (1936)

(30) R. J. W. Le Fevre, D. V. Radford, G. L. D. Ritchie, and P. J. Stiles, J. Chem. Soc. B, 150 (1968).

(31) B. B. More, W. S. Wilcox, and J. H. Goldstein, J. Chem. Phys., 22, $876(1954)$.

(32) A. Sharpe and S. Walker, J. Chem. Soc., 257 (1962).

(33) P. J. Buckley, C. C. Costain, and J. E. Parkin, Chem. Commun., 668 (1968)

(34) T. Oka, K. Tsuchiya, S. Iwata, and Y. Morino, Bull. Chem. Soc. Jpn. 37, 4 (1964)

(35) R. J. W. Le Fevre, A. Sundaram, and R. K. Pierens, J. Chem. Soc., 479 (1963).

(36) L. J. Nugent, D. E. Maun, and R. D. Lide Jr., J. Chem. Phys., 36, $965(1962)$

(37) R. J. W. Le Ferre, B. J. Orr, and G. L. D. Ritchie, J. Chem. Soc., $2499(1965)$

(38) M. D. Gregory, H. R. Affsprung, and S. D. Christian, J. Phys. Chem., 72, $1748(1968)$

(39) A. L. McClellan, ref 3, p 82 solutions of concentrations between 0.0007 and 0.003 weight fraction) were prepared for the measurements. The results are listed in Table II. The properties of pure solutes and solvents were as follows:

$\begin{array}{lll}\text { acetone } & \bar{V}_{2}=1.27486 & n_{2}=1.35596 \\ \mathrm{HCCl}_{3} & \bar{V}_{2}=0.67573 & n_{2}=1.44293 \\ \mathrm{Me}_{2} \mathrm{SO} & \bar{V}_{2}=0.91261 & n_{2}=1.47731 \\ \text { benzene } & \epsilon_{1}=2.2730 & \\ \mathrm{CCl}_{4} & \epsilon_{1}=2.2276 & \\ \text { cyclohexane } & \epsilon_{1}=2.1048 & \end{array}$

\section{Discussion}

Table I shows the well-established fact that known procedures do not lead to agreement between solution and vapor-phase values of the molecular dipole moment. Furthermore, it also shows that eq II can be used as an alternative for calculations in general.

On the other hand, both Tables I and II indicate that when eq II is used, there are a number of cases where agreement is very good, but with no regularity among solvents. Cyclohexane appears adequate for alcohols, acetone, and ethers, benzene for aromatics and water, and $\mathrm{CCl}_{4}$ for halogenated compounds and $\mathrm{Me}_{2} \mathrm{SO}$, thus suggesting a possible criterion for solvent selection.

Therefore, to a first approximation, when solute/solvent interactions are absent in highly dilute solutions, eq II gives calculated dipole moment values that agree well with vapor-phase measurements. However, as is the case with benzene as solvent, ${ }^{10}$ interactions have been established unequivocally in many binary systems. $^{42}$ But their prediction and influence on measurements are still matters open to considerable discussion.

\section{Conclusion}

Although global applicability cannot be claimed for eq II, its simple experimental requirements provide a very convenient procedure to calculate molecular dipole moment values that are in good agreement with the results from vapor-phase measurements.

Acknowledgment. The continuing support of the Consejo Nacional de Investigaciones Cientificas y Técnicas is gratefully acknowledged.

(40) M. Barón, An. Asoc. Quim. Argent., 64, 383 (1976).

(41) A. L. McClellan, ref 3, pp 33, 82, 65 .

(42) C. N. Rao, S. Sing, and V. P. Senthilnathan, Chem. Soc. Rev., 5, 297 